\title{
Conservative Treatment of Paraplegia Following Acute Trauma in a Patient with Tuberculous Kyphosis: Case Report and Review of the Literature
}

\author{
K. M. Chan, M.B., B.S., F.R.C.S.(E), F.R.C.S.(G), M.Ch. (Orth), \\ F.R.C.S. Ed. (Orth) and P. C. Leung, M.B., B.S., M.S., F.R.C.S.(E), \\ F.R.A.C.S. \\ Department of Orthopaedic and Traumatic Surgery, The Chinese University of \\ Hong Kong, Shatin, N.T., Hong Kong.
}

\begin{abstract}
Summary
This is the third known reported case in the medical literature of complete paraplegia following acute trauma in a patient with tuberculous kyphosis. Early clinical evidence of neurological recovery and the absence of a radiological fresh lesion are important indications for conservative treatment. The patient made a complete recovery. The mechanism of injury is probably both mechanical and vascular. Key words: Tuberculous kyphosis; Traumatic paraplegia; Conservative treatment .
\end{abstract}

\section{Introduction}

Neurological complications in patients with congenital kyphoscoliosis are usually associated with an insidious onset and are subsequently of a progressive nature (Winter et al., 1973). In acquired kyphosis the onset of a neurological complication is usually more acute and the aetiology of cord compression is generally the result of external factors other than the kyphoscoliosis itself, such as infection or tumour infiltration.

Paraplegia following acute trauma in a kyphotic patient due to tuberculosis is uncommon. Only two such cases have been reported in the medical literature (Schneider, 1980; Cho and Myas, 1977). The patient presented here is unique in that the cause of the kyphosis was a tuberculous infection and this is therefore, probably the first case of such a nature recorded.

\section{Case report}

A 27-year-old Chinese man was admitted to the Orthopaedic Department, Princess Margaret Hospital, Hong Kong for management of spinal injuries after a traffic accident. He was a known case of tuberculous kyphosis since the age of two and had been regularly followed up at the tuberculosis clinic. His lesions in the spine and chest had been thoroughly treated and were considered to be quiescent for many years. In spite of a severe kyphosis he was fully ambulatory 
and worked in a metal factory. No neurological problems were experienced before the accident.

Four hours prior to admission he fell from his motorcycle whilst travelling at about 45 miles per hour, hitting a ramp. There was a transient period of loss of consciousness and, when he attempted to get up, found that he was unable to move his legs and felt a sharp deep pain in his back, and numbness radiating from both thighs down the feet.

On admission his general condition was found to be stable. There was complete absence of sensation below $\mathrm{T} 12$, including all of the sacral dermatones, and complete paralysis of the lower limbs. Deep tendon reflexes were absent, as were the plantar reflexes, and there was complete loss of urinary and bowel sphincter control.

$\mathrm{X}$-rays were taken of the spine, and these showed a marked kyphotic deformity measuring about $120^{\circ}$ with the apex at the T10 level. Tomographic study was performed but there was no evidence of acute fracture or dislocation.

In view of the presence of spinal shock the patient was initially treated conservatively with complete bed rest, while the vital signs and the neurological status were continuously monitored.

Two days after the injury the deep tendon reflexes returned and became hyperactive in the lower extremities: there were bilateral ankle clonus and bilateral Babinski reflexes. Five days after admission motor recovery (grade 1) was first noted in the left great toe extensor. In the subsequent week there was gradual recovery of motor and sensory functions; grade 2 for the ankle dorsiflexor on the right side, on the left side and for knee flexors and extensors on both sides. Pin-prick sensation was demonstrated at $\mathrm{T} 12$ and $\mathrm{L}^{1}$ levels, but the deep tendon reflexes remained absent.

In view of this early neurological recovery surgical intervention was not considered necessary and a myelogram was not performed. By the end of the third week there was further improvement in the motor function: grade 1 for the hip flexors, extensors, abductors and adductors; 3 for the knee flexors and extensors on the left side, and 2 on the right side. The ankle dorsiflexors and plantarflexors were grade 4 bilaterally. The sensory state improved down to $\mathrm{L}^{1}$ level. The maintenance therapy consisted of passive and active assisted exercises of the lower limbs.

From the fourth to the sixth week there was progressive recovery of motor function of the more proximal groups; 5 the hip flexors and extensors of the lower limb muscles were grade 4 on the left side, and 3 on the right side. The more distal groups were grade 4, and the sensory level progressed to L3. An intensive rehabilitation programme was started and he was able to stand in the parallel bars and began to walk with assistance. Hydrotherapy was also introduced at this stage.

Four months after injury he was discharged from the rehabilitation centre with muscle strength of both legs at grade 4 . Sensation was nearly normal except over the $S 1$ area where it was moderately diminished. Mild hypertronicity was still present but the Babinski signs were absent. He could walk without special aid and was completely independent in the activities of daily living.

A final assessment was made 3 years after injury. He had resumed his normal activities, except for motorcycling. There was occasional mild backache. 
The neurological status was essentially normal except for some impairment of sensation in the $\mathrm{S} 1$ region, and the ankle jerks remained hyperactive.

There was gradual return of urinary bladder sphincter function and of bowel function over a period of 10 and 8 months respectively.

\section{Discussion}

In most kyphotic patients neurological function is usually normal, indicating a good adaptation of the spinal cord to the abnormal curvature. Biomechanical studies have shown that excessive spinal flexion causes elongation of the spinal canal and plastic deformation of the spinal cord (Breig, 1960). In the interrelationship between trauma, spinal curvature and paralysis, the potential aggravation of spinal curvature following acute trauma may lead to excessive axial tension in the cord resulting in neurological functional impairment. In addition to this mechanical force the likelihood of vascular impairment after acute trauma is also an important possible contributory factor (Roaf, 1964).

It is interesting to note that the sudden development of paraplegia after acute trauma in a patient with kyphosis appears to be extremely uncommon. A review of the literature showed that two similar cases have been reported (Schneider, 1960; Cho and Myas, 1977). Schneider (1960) reported a 10-year-old boy with thoraco-lumbar kyphoscoliosis who fell and developed complete areflexic paraplegia with a sensory level at L2. Myelography reviewed a complete block at L1. A laminectomy from T12 to L3 was done, with transposition of the compressed spinal cord. The patient made a satisfactory recovery but requiring short leg brace and a spinal brace for walking.

Cho and Myas (1977) reported a 47-year-old man with severe kyphosis who developed complete paraplegia with a sensory level at L1 after trauma. Myelography was attempted but failed. He was treated conservatively with complete bed rest and physiotherapy. Signs of motor recovery were noted as early as the 7 th day and he made a gradual recovery. After two and a half months, the muscle strength was grade 4 in the lower limbs, and he was completely independent for the activities of daily living.

Our patient demonstrated a similar progress: early signs of motor recovery and progressive improvement. He had grade 1 ankle dorsiflexion and knee flexion and extension on the 5 th day; and grade 3 ankle dorsiflexion and plantarflexion by the 12 th day. In view of these encouraging signs, coupled with the absence of radiological findings of acute fracture or dislocation, surgical intervention was considered unnecessary. Some workers do not recommend conservative treatment particularly when there is evidence of deterioration of spinal cord function. Instead, they favour surgery by an anterior decompression and stabilisation of the spine (De Palma and McKeen, 1965; McKenzie and Dewer, 1949).

The transient neurological dysfunction is more likely due to vascular impairment than mechanical compression. In our patient, the X-rays taken 3 years after the accident did not reveal any increase in the kyphosis (Fig. 1). This supported our initial decision for conservative treatment instead of an operative decompression. 


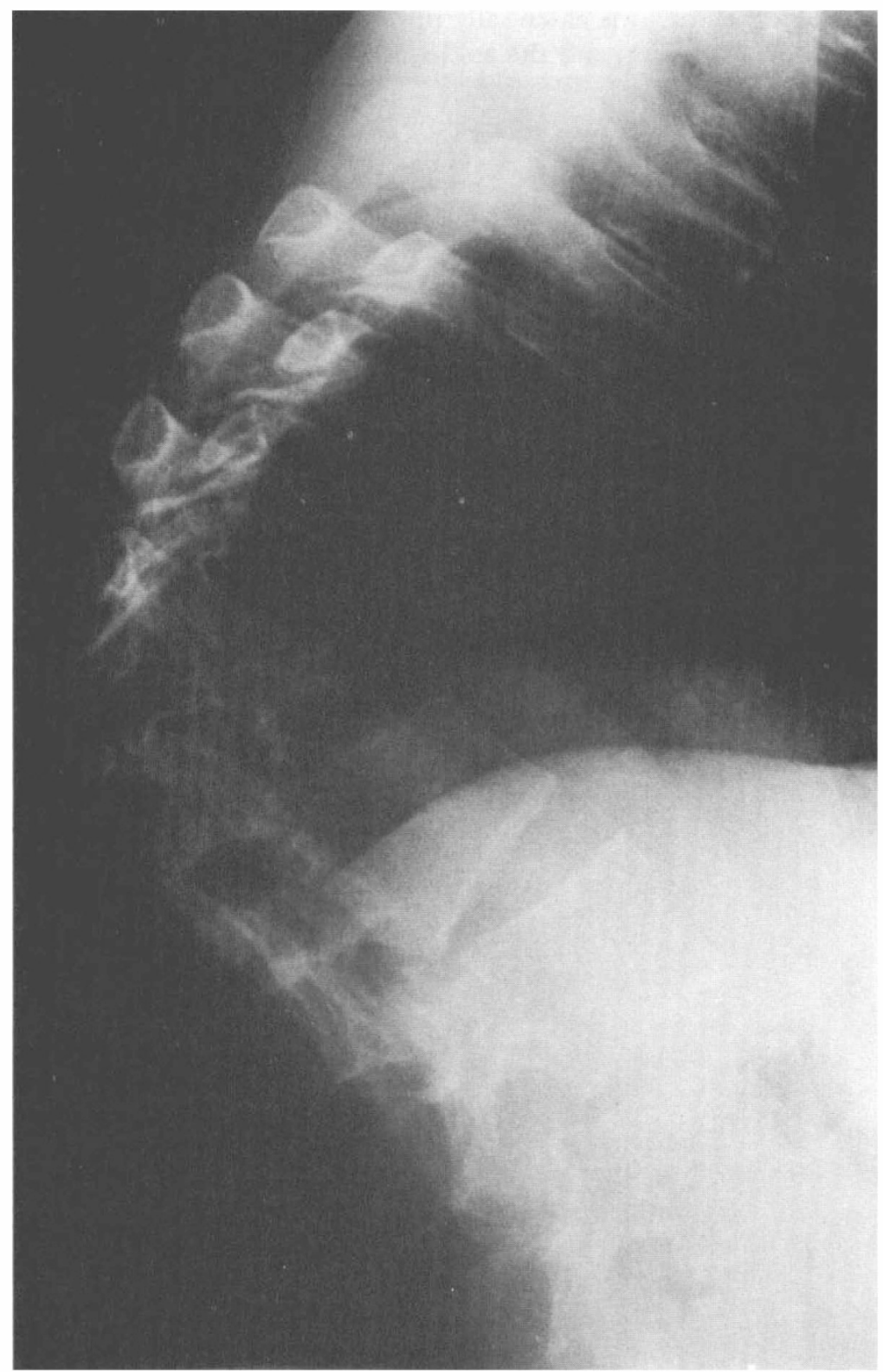

Figure 1. Lateral X-ray of the spine 3 years after the injury showing no increase in kyphosis.

\section{Résumé}

C'est ici le troisième cas noté, qu'on a signalé dans la littérature médicale, de paraplégie complète suivant un traumatisme aigu chez un malade qui souffre de Cyphose tuberculeuse. L'évidence clinique de première phase qui indique un rétablissement neurologique et l'absence d'une nouvelle lésion radiologique sont d'importantes indications qu'il faut un traitement conservateur. Le malade a effectué un rétablissement complet. Le mécanisme de la blessure est probablement tant mécanique que vasculaire. 


\section{Zusammerfassung}

Dies ist der dritte schon gekannte und in der medizinischen Litteratur berichtete Fall der völligen Paraplegie zufolge schweres Traumatismus bei einem Patient mit tuberkulöser Kyphose. Ein frühzeitiger Beweis der neurologischen Wiederherstellung und der Mangel an eine radiologische neue Läsion sind wichtige Andeutungen für eine knoservierende Behandlung. Der Patient is zur vollkommenen Wiederherstellung gekommen. Der Verletzungsmechanismus ist wahrscheinlich sowohl mechanisch als vaskular.

\section{References}

BREIG A 1960 Biomechanics of central nervous system: some basic normal and pathologic phenomena. Stockholm, Almqvist \& Wiksell, pp. 145-147.

Chо JH, Myas SJ 1977 Paraplegia following trauma in a patient with kyphosis. Archives of Physical Medicine and Rehabilitation 58:229-231.

DePALMA AF, MCKeEN WB 1965 Congenital kyphoscoliosis with paraplegia: case report. Clinical Orthopaedics 39:190-196.

MCKenZIE KG, Dewar FP 1949 Scoliosis with paraplegia. Journal of Bone and Joint Surgery (Br) 31:162-174.

ROAF R 1964 Spinal deformity and paraplegia. Paraplegia 2:112-119.

SCHNEIDER RC 1960 Transposition of compressed spinal cord kyphoscoliotic patients with neurological deficit: with special reference to vascular supply of the cord. Journal of Bone and Joint Surgery (Am) 42:1027-1040.

WINTER RB, MOE JE, WANG JF 1973 Congenital kyphosis: its natural history and treatment as observed in study of one hundred thirty patients. Journal of Bone and Joint Surgery (Am) 55:223-256, 274. 